correct expansion of the aortic valve prosthesis. ${ }^{1,3}$ For this reason, some authors recommend that the implantation be performed as high as possible. ${ }^{2}$ This intention might lead to malpositioning too high in the left ventricular outflow tract, however, potentially causing aortic regurgitation or, even worse, occlusion of the coronary arteries. ${ }^{5}$ It is therefore necessary for the user to find a position that respects these aspects.

The new Engager aortic valve prosthesis is designed to capture the native leaflets of the origin aortic valve with its control arms by placing it as close to the native aortic annulus as possible. ${ }^{4}$ We could prove that the resulting distance ensures not only a correct expansion of the aortic valve prosthesis but also a proper function of a previously implanted mitral valve prosthesis. This perfect positioning with respect to the localization of the two valve prostheses and the coronary arteries can be achieved just by the tactile feedback of the newly designed Engager prosthesis. A previously implanted mitral valve is no longer a challenge for the individual user.

\section{References}

1. Barbanti M, Ussia GP, Latib A, De Marco F, Fiorina C, Santoro G, et al. Transcatheter aortic valve implantation in patients with mitral prosthesis. J Am Coll Cardiol. 2012;60:1841-2

2. Gedikli O, Kutlu M, Civelek A, Ince H. Transcatheter implantation of a CoreValve aortic prosthesis in a patient with a ball-cage mechanical mitral valve. J Heart Valve Dis. 2013;22:697-700.

3. García E, Albarrán A, Heredia-Mantrana J, Guerrero-Pinedo F, Rodríguez J, Hernández-Antolín R, et al. Transcatheter aortic valve implantation in patients with a mechanical mitral valve. Rev Esp Cardiol (Engl Ed). 2011; 64:1052-5.

4. Sündermann S, Holzhey D, Bleiziffer S, Treede H, Falk V. Medtronic Engager ${ }^{\mathrm{TM}}$ bioprosthesis for transapical transcatheter aortic valve implantation. EuroIntervention. 2013;9(Suppl):S97-100

5. Laborde JC, Brecker SJ, Roy D, Jahangiri M. Complications at the time of transcatheter aortic valve implantation. Methodist Debakey Cardiovasc J. 2012; $8: 38-41$

\title{
Redo cardiac surgery in a patient with severe kyphoscoliosis and pectus carinatum: A technical challenge
}

\author{
Syed T. Hussain, MD, ${ }^{a}$ Michelle Capdeville, MD, ${ }^{\mathrm{c}}$ Samir R. Kapadia, MD, ${ }^{\mathrm{b}}$ and Nicholas G. Smedira, MD, ${ }^{\mathrm{a}}$ \\ Cleveland, Ohio
}

Video clip is available online.

Severe chest wall and spinal deformity in patients with Marfan syndrome can impair optimal operative exposure and complicate cardiac surgical operations. We report a case of very high-risk reoperative mitral valve surgery in a patient with severe kyphoscoliosis, pectus carinatum, and severe restrictive lung disease. To the best of our knowledge, successful redo cardiac surgery with such a severe chest wall deformity has not been previously reported.

\section{CLINICAL SUMMARY}

A 24-year-old patient with Marfan syndrome and previous mitral valve replacement with a mechanical valve

From the Departments of Cardiothoracic Surgery ${ }^{a}$ and Cardiovascular Medicine, ${ }^{b}$ Heart and Vascular Institute, and Department of Cardiothoracic Anesthesia, ${ }^{c}$ Anesthesia Institute, Cleveland Clinic, Cleveland, Ohio.

Disclosures: Authors have nothing to disclose with regard to commercial support.

Received for publication June 9, 2014; accepted for publication June 13, 2014; available ahead of print Aug 19, 2014.

Address for reprints: Nicholas G. Smedira, MD, Cleveland Clinic, 9500 Euclid Ave, Desk J4-1, Cleveland, OH 44195 (E-mail: smidern@ccf.org).

J Thorac Cardiovasc Surg 2014;148:e204-6

$0022-5223 / \$ 36.00$

Copyright $(2) 2014$ by The American Association for Thoracic Surgery

http://dx.doi.org/10.1016/j.jtcvs.2014.06.073 performed 10 years earlier presented with severe paravalvular regurgitation. She had severe deformity of the chest wall, with extreme kyphoscoliosis and pectus carinatum (Figures 1 and 2). She also had poor exercise tolerance, and pulmonary function testing showed severe restrictive lung disease (forced vital capacity was $22 \%$ of predicted) with negligible ventilatory reserve, portending a high risk of postoperative respiratory failure. A metabolic stress echocardiogram showed significant pulmonary hypertension with exercise. Computed tomography demonstrated extensive chest wall deformity with right-sided cardiac structures in close proximity to the sternum.

Based on these findings, the patient was deemed a very high operative risk, and an attempt was made at percutaneous device closure of the paravalvular leak (Video 1, A and $B$ ). The devices were successfully placed in the defect from the transseptal approach. While interrogating the devices before release to determine if they interfered with valve function, the devices spontaneously squeezed out of the defect, probably from somewhat unusual twisting motion of the anulus from severe kyphoscoliosis. At this time, the percutaneous closure attempt was aborted without any complications. After extensive discussions, a high-risk operation was offered.

Because of the gross chest deformity and the close proximity of cardiac structures to the sternum (Figure 1), 

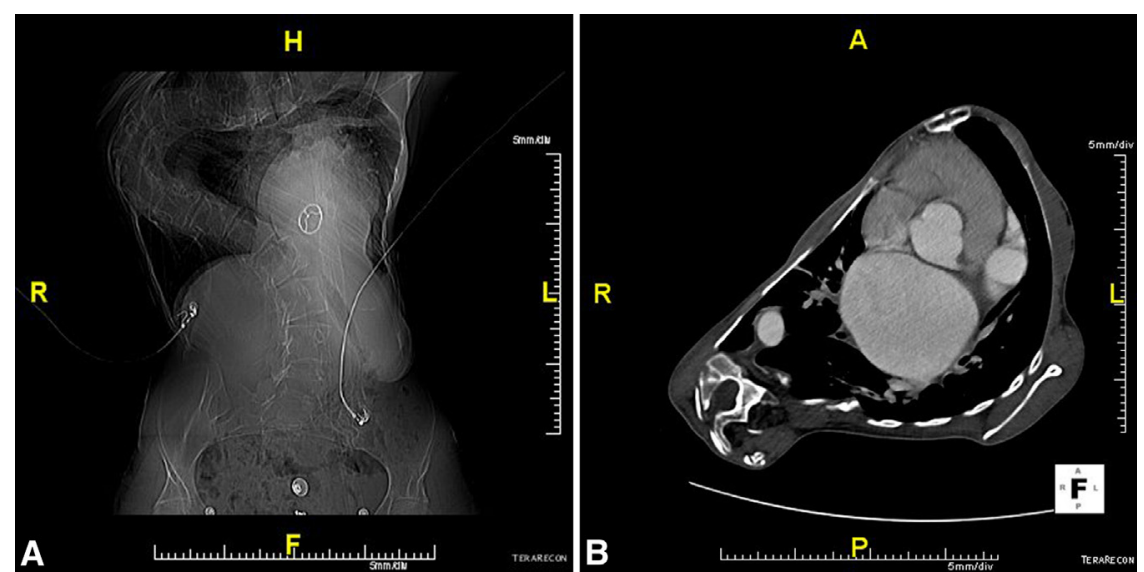

FIGURE 1. Preoperative computed tomographic imaging. A, Coronal view showing extreme kyphoscoliosis and chest wall deformity. B, Axial view showing severe chest deformity and close proximity of the cardiac structures to the sternum and chest wall.

the femoral vessels were exposed before beginning the redo sternotomy. The sternum was carefully reopened and the rest of the cardiac dissection was carried out safely, a challenging procedure because of the rotation of the heart. Nevertheless, we were able to obtain adequate operative exposure. Standard aortic and bicaval cannulation was used, and the mitral valve was approached through a left atriotomy. There were 2 separate areas of leak caused by partial valve dehiscence, so the valve was replaced with a no. 31 bileaflet mechanical prosthesis. The patient was initially extubated on postoperative day 1 , but had to be reintubated after 2 days and required tracheostomy for respiratory failure. She was eventually weaned off the ventilator and discharged from the hospital.

\section{DISCUSSION}

The association of pectus and spinal deformities with cardiovascular diseases is well known in Marfan syndrome. ${ }^{1,2}$ The primary challenge in performing intracardiac repairs in patients with severe chest wall deformity is the difficulty of performing a midline sternotomy with symmetric retraction and adequate exposure that may be hampered by cardiac displacement and rotation. Despite these challenges, patients with severe chest wall deformity, both with and without Marfan syndrome, have been reported to safely undergo simultaneous repair of pectus deformity and cardiac lesions. ${ }^{1-5}$

Our patient's severe chest wall deformity was complicated by the need for sternal reentry and close proximity of the cardiac structures to the sternum in the presence of severe restrictive lung disease. Despite the high risk involved, she was accepted for surgery because she was very young with limited options and had failed percutaneous device closure. The midline sternotomy provided adequate exposure to allow us to successfully perform the mitral valve replacement.
Our report confirms that with proper planning and optimal surgical techniques, successful reoperative cardiac surgery can be performed in high-risk patients with severe chest wall deformity.
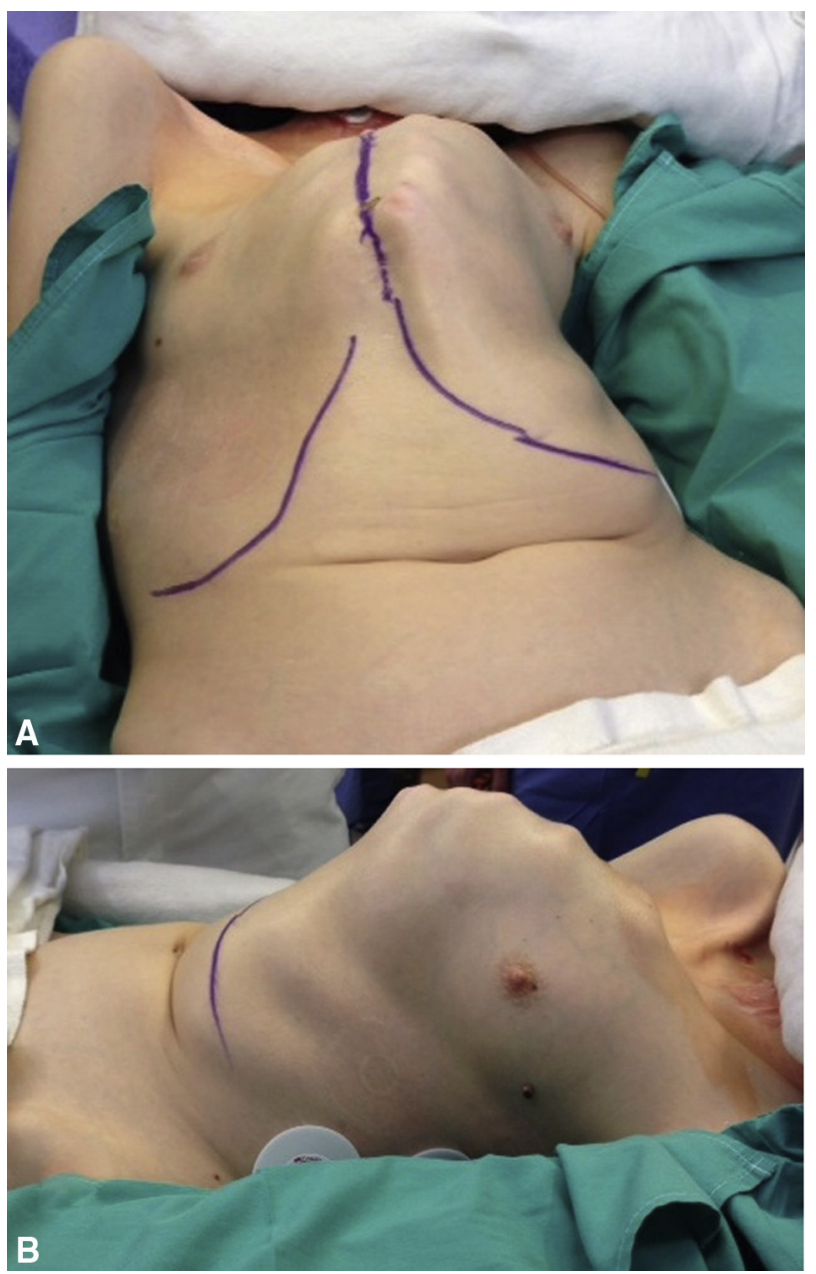

FIGURE 2. Operative photograph showing severe chest wall deformity due to extreme kyphoscoliosis and pectus carinatum. A, Frontal view. B, Lateral view. 


\section{References}

1. Javangula KC, Batchelor TJP, Jaber O, Watterson KG, Papagiannopoulos K. Combined severe pectus excavatum correction and aortic root replacement in Marfan's syndrome. Ann Thorac Surg. 2006;81:1913-5.

2. Ryu YG, Baek M-J, Kim HK, Choi YH, Sohn Y-S, Kim HJ. Simultaneous repair for aortic incompetence with annuloaortic ectasia and pectus excavatum by modified Ravitch procedure with pectus bar in an adult patient with Marfan syndrome. J Thorac Cardiovasc Surg. 2009;137:e34-6.

3. Willekes CL, Backer CL, Mavroudis C. A 26-year review of pectus deformity repairs, including simultaneous intracradiac repair. Ann Thorac Surg. 1999;67:511-8.

4. Hasegawa T, Yamaguchi M, Ohshima Y, Yoshimura N, Oka S, Ootaki Y. Simultaneous repair of pectus excavatum and congenital heart disease over the past 30 years. Eur J Cardiothorac Surg. 2002;22:874-88.

5. Fukahara K, Minami K, Hansky B, Schulte-Eistrup SA, Tenderich G, Schulz U, et al. Successful heart-lung transplant in a patient with kyphoscoliosis. J Heart Lung Transplant. 2003;22:468-73. 